\title{
Downregulation of microRNA-33a promotes cyclin-dependent kinase 6, cyclin D1 and PIM1 expression and gastric cancer cell proliferation
}

\author{
YUDONG WANG $^{1}$, XINLIANG ZHOU $^{1}$, BAOEN SHAN $^{2,3}$, JING HAN $^{1}$, \\ FEIFEI WANG ${ }^{2}$, XIAOJIE FAN ${ }^{4}$, YALEI LV ${ }^{1}$, LIANG CHANG ${ }^{1}$ and WEI LIU ${ }^{1}$ \\ ${ }^{1}$ Department of Oncology; ${ }^{2}$ Research Center; ${ }^{3}$ Tumor Research Institute; ${ }^{4}$ Department of Pathology, \\ The Fourth Hospital of Hebei Medical University, Shijiazhuang, Hebei 050011, P.R. China
}

Received November 13, 2014; Accepted August 4, 2015

DOI: $10.3892 / \mathrm{mmr} .2015 .4296$

\begin{abstract}
Although microRNA-33 (miR-33) family members are known to be involved in the regulation and balancing of cholesterol metabolism, fatty acid oxidation and insulin signaling, their functions in carcinogenesis are controversial and the underlying mechanisms have remained elusive. Gastric cancer is the fourth most common malignancy in the world; however, the dysregulation and function of miR-33 family members in gastric cancer have not been extensively studied. The present study reported that a miR-33 family member, miR-33a, was significantly downregulated in gastric cancer tissues and gastric cancer cell lines. Of note, the expression of miR-33a was inversely correlated with pathological differentiation and metastasis as well as gastric cancer biomarker CA199. A cell-counting kit-8 assay showed that transfection of the SGC-7901 gastric cell line with miR-33a-overexpression plasmid inhibited the capability of the cells to proliferate. Furthermore, overexpression of miR-33a led to cell cycle arrest of SGC-7901 cells in G1 phase. In addition, a luciferase reporter assay showed that miR-33a directly targeted cyclin-dependent kinase 6 (CDK6), cyclin D1 (CCND1) and serine/threonine kinase PIM-1. In gastric cancer specimens, the reduced expression of miR-33a was associated with increased expression of CDK-6, CCND1 and PIM1. However, only PIM1 expression was significantly increased in cancer tissues compared with that in their adjacent tissues. The present study revealed that miR-33a was downregulated in gastric cancer tissues and cell lines, while forced overexpression of miR-33a decreased CDK-6, CCND1 and PIM1 expression to inhibit gastric cancer cell proliferation by causing G1 phase arrest. miR-33a
\end{abstract}

Correspondence to: Professor Wei Liu, Department of Oncology, The Fourth Hospital of Hebei Medical University, 12 Jiankang Road, Shijiazhuang, Hebei 050011, P.R. China

E-mail: liuweiphd@hotmail.com

Key words: microRNA-33a, gastric cancer, proliferation, G1 phase, target genes overexpression may therefore resemble an efficient strategy for gastric cancer therapy.

\section{Introduction}

MicroRNAs (miRNAs/miRs) are non-coding, single-stranded RNAs of 21 to 23 nucleotides in length that post-transcriptionally regulate gene expression (1). miRNAs regulate the expression of an estimated $30 \%$ of all mRNAs in humans (1). To date, thousands of miRNAs have been identified in the human genome, and were found to have critical roles in a wide array of physiological and pathological processes (2). Of note, it has been revealed that the dysregulation of miRNAs is implicated in cancer (3-7). The miR-33 family, including miR-33a and miR-33b, are encoded within the intronic sequences of the Srebp genes in organisms (8-11). miR-33a is located in intron 16 of the Srebp-2 gene on chromosome 22 and miR-33b is present in intron 17 of the Srebp-1 gene on chromosome 17 (12). The miR-33 family were reported to be involved in the regulation and balancing of cholesterol metabolism, fatty acid oxidation and insulin signaling (12-15). Several recent studies reported that miR-33a was involved in several malignancies, including lung cancer (16), hepatocellular carcinoma (17), colon cancer (18), osteosarcoma (19) and supraglottic carcinoma (20). However, studies regarding miR-33a expression in various tumor types are controversial. Certain studies reported miR-33a to be upregulated in supraglottic (20) and intestinal-type gastric cancer tissues (21), while other studies showed that miR-33a was downregulated in metastatic lung cancer (22). Contradictory results were also reported regarding the functions of miR-33a in cancer. While certain studies reported that miR-33a promoted tumorigenesis (23), cancer progression (18) and drug resistance (19), of human colon cancer, osteosarcoma and hematopoietic stem cells, others reported that miR-33a inhibited the proliferation $(24,25)$, migration and invasion $(16,22)$ of lung cancer and lymphoma. Gastric cancer is the fourth most common malignancy in the world and the second leading cause of cancer mortality. More than $70 \%$ of new cases and mortalities occur in developing countries, particularly in China (26). However, to the best of our knowledge, the roles of miR-33a in gastric cancer have not been studied. The expression and functions of miR-33a in gastric 
Table I. Sequences of primers used for PCR.

\begin{tabular}{ll} 
Primer name & \multicolumn{1}{c}{ Primer sequence (5'-3') } \\
\hline hsa-miR-33a-RT & GTCGTATCCAGTGCGTGTCGTGGAGTCGGCAATTGCACTGGATACGACTGCAAT \\
hsa-miR-33a-PCR & GGCCGTGCATTGTAGTTGC \\
hsa-miR-33b-RT & GTCGTATCCAGTGCGTGTCGTGGAGTCGGCAATTGCACTGGATACGACGCAATG \\
hsa-miR-33b-PCR & GGCGTGCATTGCTGTTGC' \\
U6-RT & CGCTTCACGAATTTGCGTGTCAT \\
U6-PCR & GCTTCGGCAGCACATATACTAAAAT \\
UNP & CAGTGCGTGTCGTGGAGT \\
CDK6-F & GAGTCTGATTACCTGCTCCGC \\
CDK6-R & CCGGAGATCGGTCTAGCTTT \\
CCND1-F & GATGCCAACCTCCTCAACGA \\
CCND1-R & GGAAGCGGTCCAGGTAGTTC \\
PIM1-F & CTGGGGAGAGCTGCCTAATG \\
PIM1-R & AAGAGATCTTGCACCGGCTC \\
P53-F & CTGCCCTCAACAAGATGTTTG \\
P53-R & CTATCTGAGCAGCAGCGCTCATGG \\
18S-F & CAGCCACCCGAGATTGAGCA \\
18S-R & TAGTAGCGACGGGCGGTGTG \\
CDK6 3'UTR-F & GACTAGTGTCCCCTCAGCAAGC \\
CDK6 3'UTR-R & CCCAAGCTTCAAATCAGGCCCGGCAGCTGC \\
CCND1 3'UTR-F & GACTAGTAGAGAACAGG \\
CCND1 3'UTR-R & CCCAAGCTTATTGTTTTTTCCACCT \\
PIM1 3'UTR-F & GACTAGTTGTCAGATGCCCGAGGG \\
PIM1 3'UTR-R & CCCAAGCTTAATAAGATCTCTTTTATCCCCTGT \\
P53 3'UTR-F & GACTAGTCCTCCGGAGTAGCTGG \\
P53 3'UTR-R & CCCAAGCTTGATCGATATAAAAATGGG \\
&
\end{tabular}

RT, reverse transcription; PCR, polymerase chain reaction; UNP, universal primer; F, forward; R, reverse; UTR, untranslated region; miR, microRNA; hsa, Homo sapiens.

cancer, particularly in clinical specimens, have remained to be elucidated.

Although surgery is the most effective treatment for localized gastric cancer, $\sim 50 \%$ of all patients have recurrences following curative resection. Even though traditional chemotherapy is effective in these cases, the prognosis of gastric cancer patients remains poor (27-29). Novel and effective molecular targets, such as miRNAs, for treating gastric cancer are therefore urgently required. The present study examined miR-33a expression in gastric cancer specimens and cell lines and investigated its correlation with clinicopathological factors as well as gastric cancer-associated antigens and gene expression. The effects of miR-33a overexpression on the proliferation and cell cycle progression of the SGC-7901 gastric cancer cell line as well as gene expression were assessed. A luciferase reporter assay was employed to identify direct target proteins of miR-33a. The present study indicated that miR-33a may be a biomarker and a molecular target for gastric cancer therapy.

\section{Materials and methods}

Reagents and apparatus. In the present study, the following reagents and apparatus were used: miRNeasy Mini kit (Qiagen,
Valencia, CA, USA), a NanoDrop ND-1000 (NanoDrop Technologies, Wilmington, DE, USA), GoTaq ${ }^{\circledR}$ qPCR Master mix (Promega Corp., Madison, WI, USA), RevertAid First Strand RevertAid First Strand cDNA Synthesis kit (Thermo Fisher Scientific, Waltham, MA, USA), primers (shown in Table I; Invitrogen Life Technologies, Inc., Carlsbad, CA, USA), ABI 7500 thermocycler (Applied Biosystems, Thermo Fisher Scientific), miScript miR-33a mimic (Qiagen), miScript miR-33a inhibitor (Qiagen), AllStars Negative Control small interfering (si)RNA (Qiagen), miScript Inhibitor Negative control (Qiagen), HiperFect transfection reagent (Qiagen), Transwell inserts (pore size, $8 \mu \mathrm{m}$; Corning-Costar, Corning, NY, USA), Matrigel basement membrane matrix (BD Biosciences, Bedford, MA, USA), Giemsa (Sigma-Aldrich, St. Louis, MO, USA), pGL3 control vector (Promega Corp.), pRL-TK (Promega Corp.), Dual-Luciferase Reporter Assay system (Promega Corp), Protein bicinchoninic acid (BCA) Assay kit (Bio-Rad Laboratories Inc., Hercules, CA, USA), polyvinylidene difluoride membranes (Millipore, Billerica, MA, USA), anti-PIM1 (rabbit monoclonal, Abcam, Cambridge, MA, USA; cat. no. ab75776; 1:15,000), anti-p53 (rabbit monoclonal; Abcam; cat. no. ab179477; 1:3,000), anti-CDK6 (rabbit monoclonal; Abcam; cat. no. ab124821; 1:100,000), 
anti-CCND (rabbit monoclonal; Abcam; cat. no. ab16663; 1:200), anti- $\beta$-actin (rabbit polyclonal antibody, Santa Cruz Biotechnology, Inc., Dallas, TX, USA; cat. no. sc-130657; 1:500) and anti-rabbit IgG VHH Single Domain antibody (HRP) (Abcam; cat. no. ab191866; 1:5,000).

Cell culture and clinical specimen collection. The human gastric carcinoma cell lines MKN-28, SGC-7901, BGC-823 and HGC-27 and the gastric epithelial cell line GES-1 were provided by the Research Center of the Fourth Hospital of Hebei Medical University (Shijiazhuang, China), obtained from the Tumor Cell Bank of Chinese Academy of Medical Sciences (Beijing, China). Cells were cultured in $10-\mathrm{cm}^{2}$ dishes (BD Biosciences, Franklin Lakes, NJ, USA) in Dulbecco's modified Eagle's medium or RPMI-1640 (Gibco Life Technologies, Carlsbad, CA, USA) and incubated at $37^{\circ} \mathrm{C}$ with humidified $5 \% \mathrm{CO}_{2}$. The protocol for the collection of clinical specimens and the study protocol were approved by the Ethics Committee of Hebei Medical University (Shijiazhuang, China). All participants provided written informed consent. A total of 57 gastric carcinoma tissues and paired adjacent tissues were retrieved from surgical pathology files at the Forth Hospital of Hebei Medical University (Shijiazhuang, China). None of the patients had received pre-operative irradiation or chemotherapy. Information regarding age, gender, histological grade, differentiation status of adenocarcinoma, stage, tumor size/invasion depth (T), tumor embolus, degree of lymph node invasion $(\mathrm{N})$ and distant metastasis $(\mathrm{M})$ was retrieved from patient charts. The pre-treatment of the tissues was performed as previously described (30). Only sections containing a minimum of $90 \%$ carcinoma cells by examination with hematoxylin-eosin staining (Promega Corp.) were used for total RNA preparation (Fig. 1).

Total RNA isolation and reverse transcription quantitative polymerase chain reaction ( $R T-q P C R)$. Total RNA, including miRNA, was isolated from frozen gastric carcinoma tissues, the paired adjacent tissues and cell lines using the miRNeasy Mini kit according to the manufacturer's instructions. RNA purity and concentration were confirmed by spectrophotometry using the NanoDrop ND-1000. RT-qPCR analysis was performed using the RevertAid First Strand cDNA Synthesis kit and the GoTaq $^{\circledR}$ qPCR Master Mix according to the manufacturer's instructions in an ABI 7500 thermocycler. PCR primers are shown in Table I. The thermocycling conditions were as follows: $95^{\circ} \mathrm{C}$ for $2 \mathrm{~min}, 95^{\circ} \mathrm{C}$ for $15 \mathrm{sec}$ for 40 cycles, $60^{\circ} \mathrm{C}$ for $1 \mathrm{~min}$ for 40 cycles, $95^{\circ} \mathrm{C}$ for $15 \mathrm{sec}, 60^{\circ} \mathrm{C}$ for $15 \mathrm{sec}$ and $95^{\circ} \mathrm{C}$ for $15 \mathrm{sec}$. The fold-change for each miRNA and mRNA, relative to U6 and $18 \mathrm{~S}$, were calculated using the $2^{-\Delta \Delta \mathrm{Ct}}$ method. Three independent RT-PCR reactions were performed.

Transfection of miScript miRNA mimic and inhibitor. SGC-7901 cells $\left(1 \times 10^{5}\right)$ were transfected with $5 \mathrm{nM}$ miScript miR-33a mimic, $50 \mathrm{nM}$ miScript miR-33a inhibitor, $5 \mathrm{nM}$ AllStars Negative Control siRNA or $50 \mathrm{nM}$ miScript Inhibitor Negative Control using a HiperFect transfection Reagent according to the manufacturer's instructions.

Cell proliferation assay. SGC-7901 cells transfected with miR-33a mimics (5 nM), inhibitor (50 nM) or Allstars negative

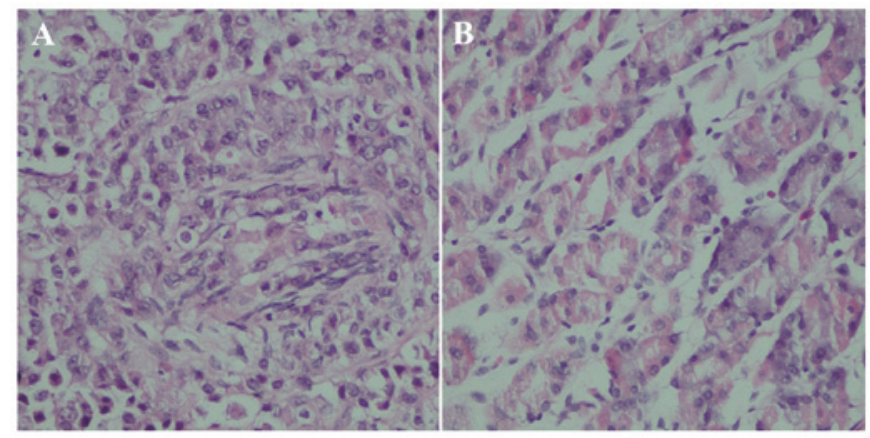

Figure 1. Hematoxylin-eosin staining analysis of (A) gastric cancer tissue and (B) adjacent tissue (magnification, x200).

control siRNA (50 $\mathrm{nM}$ ) were seeded in 96-well plates at a density of $5 \times 10^{3}$ cells per well for the indicated time intervals. Cell proliferation was assessed using the Cell Counting Kit-8 (CCK-8; Dojindo, Kumamoto, Japan) as described previously (31).

Cell cycle analysis. SGC-7901 cells transfected with miR-33a mimics $(5 \mathrm{nM})$, inhibitor $(50 \mathrm{nM})$ or Allstars negative control siRNA $(50 \mathrm{nM})$ were seeded in cell culture plates and incubated for 24, 48 and $72 \mathrm{~h}$. At the end of the incubation, the cells were washed twice with ice-cold phosphate-buffered saline (PBS), fixed in $70 \%$ cold ethanol, treated with $100 \mu \mathrm{g} / \mathrm{ml}$ ribonuclease A (Roche Diagnostics, Basel, Switzerland) and labeled with $50 \mu \mathrm{g} / \mathrm{ml}$ propidium iodide (PI; Sigma-Aldrich) for $30 \mathrm{~min}$ at $37^{\circ} \mathrm{C}$. The cells were analyzed using the FACScalibur ${ }^{\mathrm{TM}}$ system (BD Biosciences) in conjunction with CellQuest software (BD Biosciences) (32).

Luciferase reporter assays. The 3' untranslated regions (UTR) in the gene promoters of PIM1, P53, CDK6 and CCND1 were PCR-amplified from genomic DNA and inserted into the pMIR control vector using the SpeI and HindIII restriction sites. PCR primers used to amplify the PIM1, P53, CDK6 and CCND1 3'UTRs are listed in Table I. SGC-7901 cells were co-transfected with $2 \mu \mathrm{g}$ firefly luciferase reporter vector and $0.5 \mu \mathrm{g}$ control vector containing Renilla luciferase pRL-TK vector. For each group, $20 \mathrm{nM}$ of the miR-33a mimic or AllStars Negative Control siRNA was used. Firefly and Renilla luciferase activities were measured consecutively using the dual luciferase system at $48 \mathrm{~h}$ after transfection.

Western blot analysis. Cell extracts were prepared and protein concentration in the lysates was measured using the Protein BCA Assay kit. Western blot analysis was performed as described previously (33). The antibodies used for western blotting were PIM1, P53, CDK6 and CCND1. An anti- $\beta$-actin antibody was used as a protein loading control. Primary antibodies were applied at $4^{\circ} \mathrm{C}$ overnight. The secondary antibody was incubated at room temperature for $1 \mathrm{~h}$.

Statistical analysis. The expression levels of miRNAs from tissues were compared by using the Wilcoxon Signed Ranks test, the Mann-Whitney U test or the Kruskal-Wallis test. A Multiple linear regression analysis was performed to analyze the combined effects of clinicopathological features. The cell 


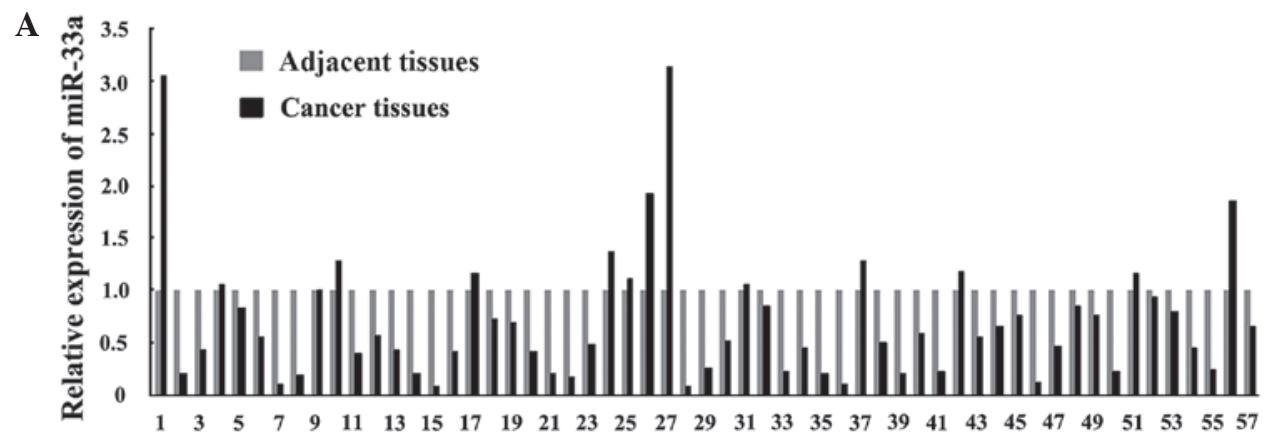

B

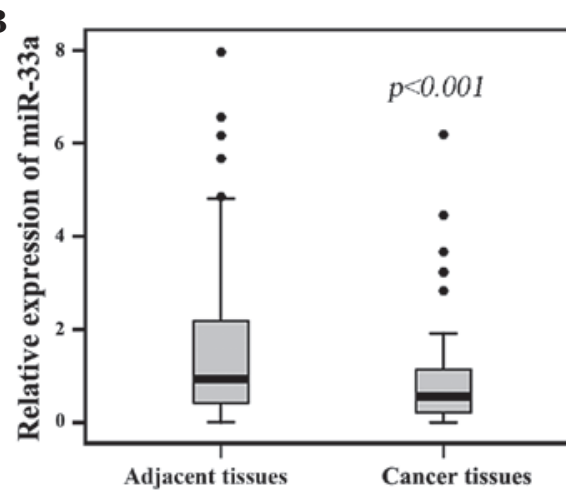

C

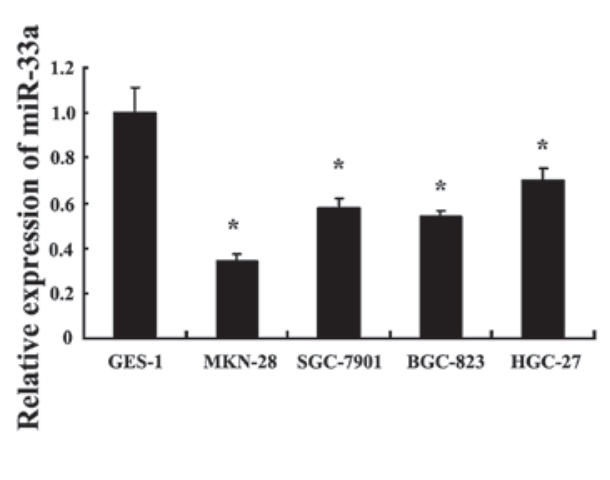

Figure 2. Differential expression of miR-33a in gastric cancer tissues and cell lines. (A) RT-qPCR analysis of gastric cancer tissues and paired adjacent tissues showing significantly decreased miR-33a expression in gastric cancer tissues. Expression in the paired adjacent tissues was set as 1. (B) Box plot analysis of differential miR-33a expression in gastric cancer tissues and paired adjacent tissues showing a significantly lower expression in gastric cancer (Wilcoxon signed ranks test). (C) Relative expression of miR-33a in four gastric cancer cell lines and the gastric epithelial cell line GES-1 were determined by RT-qPCR. Values are expressed as the mean \pm standard deviation from at least three separate experiments. "P<0.05 vs. GES-1. miR, microRNA; RT-qPCR, reverse transcription quantitative polymerase chain reaction.

experimental data were analyzed by using the t-test. A P-value of less than 0.05 was considered to indicate a statistically significant difference. All analyses were performed using SPSS 13.0 software (SPSS, Inc., Chicago, IL, USA).

\section{Results}

miR-33a is downregulated in gastric cancer. To evaluate the expression of miR-33 family members in gastric cancer tissues, RT-qPCR was used to detect the expression levels in 57 pairs of tumor tissues and their matched adjacent tissues. In comparison with the adjacent tissues, miR-33a was downregulated in $75.4 \%(43 / 57)$ of the tumor samples. The expression of miR-33a in gastric cancer tissues was significantly lower than that in their matched adjacent tissues (Fig. 2A and B). While miR-33b was downregulated in $56.1 \%$ (32/57) of the tumor samples, its expression was not significantly different between gastric cancer tissues and normal adjacent tissues (data not shown). Similarly to the expression in cancer tissue specimens, miR-33a was reduced in the gastric cancer cell lines compared to that in the normal gastric cell line GES-1 (Fig. 2C).

miR-33a levels are inversely correlated with pathological differentiation and distant metastasis $(M)$. Next, the present study determined the potential clinicopathological implications of altered miR-33a expression in gastric cancer. All data of the patients who donated the tissue samples, including age, gender, pathological differentiation, tumor-nodes-metastasis (TNM) stage, tumor size/invasion depth (T), lymph node metastasis $(\mathrm{N}), \mathrm{M}$ and venous invasion were obtained from clinical and pathological records. In the 57 patients with gastric cancer, miR-33a expression was associated with pathological differentiation, TNM stage, T and M, but not with age, gender, $\mathrm{N}$ and venous invasion (Table II and Fig. 3). To analyze the combined effects of pathological differentiation, T, N, M and venous invasion on miR-33a expression, a multiple linear regression analysis was performed using these clinicopathological features. The results showed that miR-33a expression was inversely correlated with pathological differentiation and $\mathrm{M}$ (Table III). In addition, the expression of miR-33a was negatively correlated with gastric cancer biomarker CA199 (Table IV). These results suggested that miR-33a had critical roles in the proliferation, invasion and metastasis of gastric cancer.

miR-33a inhibits cell proliferation and causes $G_{1}$-phase arrest. To investigate the biological effects of miR-33a, the present study assessed the changes in cell proliferation, cell cycle of the gastric cancer cell line SGC-7901 transfected with vectors expressing miR-33a mimic or inhibitor. RT-qPCR analysis showed that the forced overexpression (Fig. 4A) and knockdown (Fig. 4B) of miR-33a were successful. Transfection of miR-33a mimic significantly inhibited the capacity of SGC-7901 cells to proliferate and arrested cells in $G_{1}$ phase, while the transfection with miR-33a inhibitor significantly increased cell proliferation (Fig. 4B and C). In addition, the effects of miR-33a overexpression or knockdown on the migratory and invasive properties of SGC-7901 cells were assessed using Transwell and wound healing assays; however, no differences between transfected and control cells 
Table II. Correlation between the expression of microRNA-33a in gastric cancer specimens with clinicopathological features.

\begin{tabular}{|c|c|c|c|c|}
\hline Clinicopathological feature & Number & Median & Interquartile range & P-value \\
\hline Gender & & & & $0.211^{\mathrm{a}}$ \\
\hline Male & 53 & 0.560 & 0.768 & \\
\hline Female & 4 & 0.433 & 0.656 & \\
\hline Age (years) & & & & $0.127^{\mathrm{a}}$ \\
\hline$\leq 65$ & 41 & 0.554 & 0.707 & \\
\hline$>65$ & 16 & 0.728 & 0.633 & \\
\hline Pathological differentiation & & & & $0.001^{\mathrm{a}}$ \\
\hline Well/moderate & 20 & 0.899 & 0.619 & \\
\hline Poor & 37 & 0.431 & 0.538 & \\
\hline TNM stage & & & & $0.002^{\mathrm{b}}$ \\
\hline IB & 2 & 0.833 & 0.092 & \\
\hline IIB & 6 & 0.431 & 0.328 & \\
\hline IIIA & 14 & 0.789 & 0.450 & \\
\hline IIIB & 12 & 0.575 & 0.837 & \\
\hline IIIC & 17 & 0.761 & 0.712 & \\
\hline IV & 6 & 0.190 & 0.119 & \\
\hline $\mathrm{T}$ & & & & $0.005^{\mathrm{b}}$ \\
\hline $\mathrm{T} 1 \mathrm{~b}$ & 2 & 0.833 & 0.092 & \\
\hline $\mathrm{T} 4 \mathrm{a}$ & 57 & 0.595 & 0.748 & \\
\hline $\mathrm{T} 4 \mathrm{~b}$ & 4 & 0.139 & 0.102 & \\
\hline $\mathrm{N}$ & & & & $0.113^{\mathrm{b}}$ \\
\hline N0 & 8 & 0.495 & 0.483 & \\
\hline $\mathrm{N} 1$ & 14 & 0.789 & 0.450 & \\
\hline N2 & 12 & 0.574 & 0.837 & \\
\hline N3a & 17 & 0.525 & 0.938 & \\
\hline N3b & 6 & 0.190 & 0.673 & \\
\hline M & & & & $0.001^{\mathrm{a}}$ \\
\hline M0 & 51 & 0.666 & 0.576 & \\
\hline M1 & 6 & 0.190 & 0.119 & \\
\hline Venous invasion & & & & $0.643^{\mathrm{a}}$ \\
\hline Negative & 36 & 0.557 & 0.703 & \\
\hline Positive & 21 & 0.595 & 0.932 & \\
\hline
\end{tabular}

${ }^{\mathrm{a}}$ Mann-Whitney U test; ${ }^{\mathrm{K}}$ Kruskal-Wallis test. T, tumor; N, nodes; M, metastasis.

were observed (data no shown). miR-33a mimic significantly arrested cells in the G1 phase.

miR-33a directlytargets CDK6, CCND1 and PIM1 in SGC-7901 gastric cancer cells. To reveal how miR-33a suppresses gastric cancer cell proliferation, Targetscan (http://www.targetscan. org/) and Miranda (http://www.microrna.org/) were used to identify miR-33a targets in human gastric cancers. Among these candidate target genes, cyclin-dependent kinase (CDK6), cyclin (CCN)D1, PIM1 and p53 were predicted to be miR-33a targets (Fig. 5A). CDK6 and CCND1 regulate cell cycle progression from $\mathrm{G} 1$ to $\mathrm{S}$ phase (34). Downregulation of CDK6 and CCND1 leads to cell cycle arrest in G1 phase (35). PIM1 is a positive regulator at the $\mathrm{G} 2 / \mathrm{M}$ transition of the cell cycle (36) and mediates resistance to AKT inhibition (37). p53 as a tumor suppressor inhibits cell proliferation by inducing apoptosis
Table III. Combined effects of pathological differentiation, T/N/M and venous invasion on microRNA-33a expression.

\begin{tabular}{lccr}
\hline & \multicolumn{2}{l}{ Standardized coefficient } & \\
\cline { 2 - 3 } Model & $\beta$ & $\mathrm{t}$ & P-value \\
\hline Constant & & 3.422 & $<0.001$ \\
Histological grade & -0.105 & -3.164 & 0.003 \\
$\mathrm{~T}$ & -0.431 & -0.169 & 0.867 \\
$\mathrm{~N}$ & 0.247 & 1.745 & 0.087 \\
$\mathrm{M}$ & -0.186 & -2.016 & 0.049 \\
Venous invasion & -0.265 & 0.297 & 0.768 \\
\hline
\end{tabular}

T, tumor; $\mathrm{N}$, nodes; $\mathrm{M}$, metastasis. 

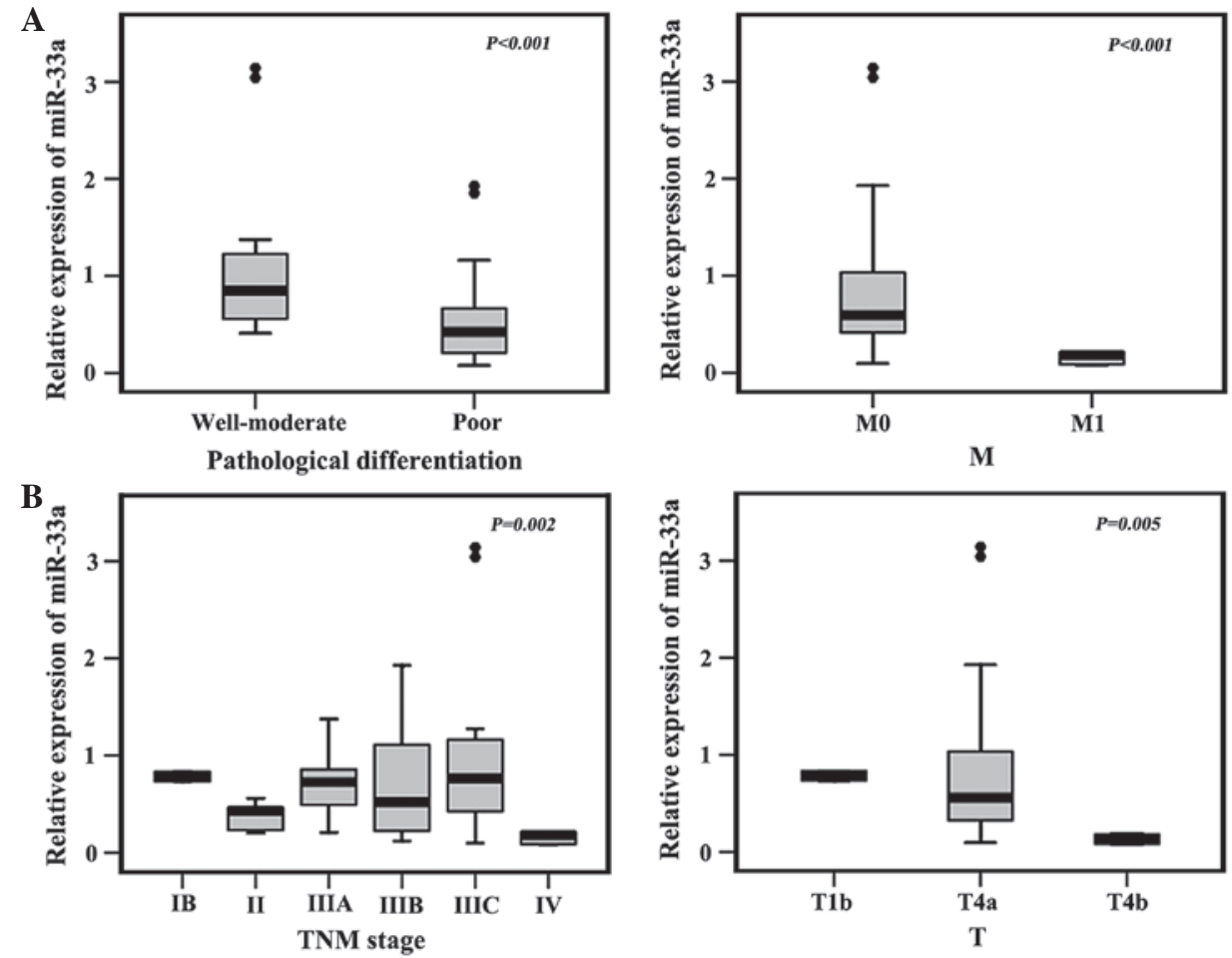

Figure 3. Correlation analysis of miR-33a expression in gastric cancer specimens with clinicopathological features. miR-33a expression levels were associated with pathological differentiation, TNM stage, T and M. (A) Analysis of pathological differentiation and M stage using the Mann-Whitney U test; (B) Analysis of TNM stage and T stage by Kruskal-Wallis test. miR, microRNA; TNM, tumor, nodes, metastasis.

and $\mathrm{G} 1$ arrest $(38,39)$. To test the direct targeting of CDK6, CCND1, PIM1 and 53 by miR-33a, their complementary site sequences were inserted into plasmids downstream of a firefly luciferase reporter gene, which were then co-transfected into SGC-7901 cells together with miR-33a mimic or scrambled oligonucleotide. Compared to the scrambled oligonucleotide transfection, the co-transfection with miR-33a caused a marked reduction in the luciferase activity of the CDK6, CCND1 and PIM1 reporter constructs (Fig. 4B). Following transfection with miR-33a mimics, protein and mRNA levels of CDK6, CCND1 and PIM1 were significantly decreased, while they were significantly increased following miR-33a inhibition $(\mathrm{P}<0.01)$ (Fig. 5C and D). In the miR-33a mimics group, CCND1 and CDK6 were downregulated to a greater extent than PIM1. The above results may indicate that miR-33a inhibited gastric cancer cell proliferation via the downregulation of CDK6, CCND1 and PIM1.

PIM1 is upregulated in gastric cancer tissues. Since the present study showed that CDK6, CCND1 and PIM1 were targets of miR-33a, the expression of CDK6, CCND1 and PIM1 in gastric cancer tissues was evaluated. To verify the direct association of miR-33a with CDK6, CCND1 and PIM1 in gastric cancer, a correlation analysis was performed, revealing that the levels of miR-33a were negatively correlated to the expression of CDK6, CCND1 and PIM1 in gastric cancer specimens (Table V). In comparison with the adjacent tissues PIM1 was upregulated in $68.4 \%$ (39/57) of the tumor samples (Fig. 6A). Furthermore, CDK6 and CCND1 were upregulated in $45.6 \%(26 / 57)$ and $54.4 \%$ (31/57) of tumor tissues, respectively, compared with those in adjacent tissues (results not shown). Quantification of the results showed that expression of PIM1 but not CDK6 and CCND1 was significantly higher in gastric cancer tissues than that in their matched adjacent normal tissues (Fig. 6B). These results indicated that miR-33a most likely has a role in gastric cancer by targeting PIM1.

\section{Discussion}

It is widely known that the miR-33 family has a critical role in cholesterol metabolism, fatty acid oxidation and regulation of insulin signaling $(12,17,40,41)$. An increasing number of studies reported that miR-33a participates in the initiation and progression of malignancies (16-20). However, previous results regarding miR-33a expression were contradictory $(21,22)$. Numerous studies have demonstrated that miR-33a expression is dysregulated in various human cancer types (16-20). However, to the best of our knowledge, miR-33a has not been previously studied in gastric cancer. The present study reported that miR-33a expression in gastric cancer tissues was significantly lower than that in their adjacent tissues. Similarly, the expression of miR-33a was reduced in gastric cancer cell lines compared to that in a normal gastric cell line. In addition, the expression of miR-33a was inversely correlated with pathological differentiation and M. Furthermore, miR-33a expression was negatively correlated with cancer biomarker CA199, which is one of the most sensitive and relevant tumor biomarkers for gastric cancer. These results collectively indicated that miR-33a may be a critical factor of proliferation, migration and invasion, as well as a potential therapeutic target for the inhibition of these processes in gastric cancer. Furthermore, similarly to CA199, miR-33a may be a useful predictive biomarker of gastric cancer. 
Table IV. Correlation of the expression of microRNA-33a with the levels of antigens CA50, CEA, CA199 and CA724 in gastric cancer specimens.

\begin{tabular}{lcccrr}
\hline & & & & \multicolumn{2}{c}{ Spearman test } \\
\cline { 5 - 6 } Antigen & Number & Median & Interquartile range & $\mathrm{r}$ & P-value \\
\hline CA50 $(\mathrm{IU} / \mathrm{ml})$ & 51 & 7.40 & 7.45 & -0.214 & 0.132 \\
$\mathrm{CEA}(\mathrm{ng} / \mathrm{ml})$ & 53 & 2.42 & 2.36 & 0.067 & 0.632 \\
$\mathrm{CA} 199(\mathrm{U} / \mathrm{ml})$ & 53 & 15.64 & 8.02 & -0.407 & 0.002 \\
CA724 $(\mathrm{U} / \mathrm{ml})$ & 53 & 2.11 & -0.100 & 0.477 \\
\hline
\end{tabular}

CEA, carcinoembryonic antigen; CA, cancer antigen.

A

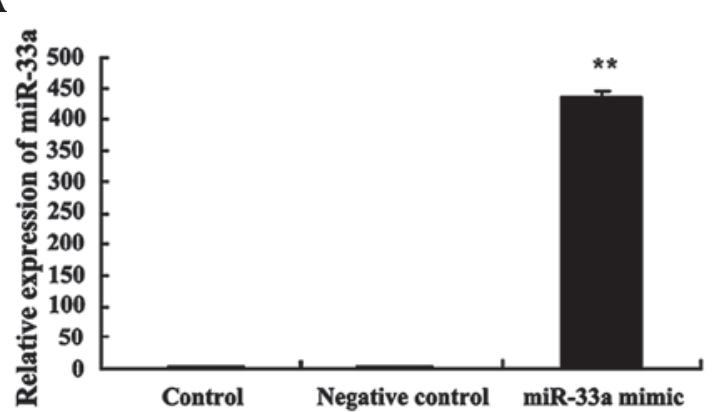

B

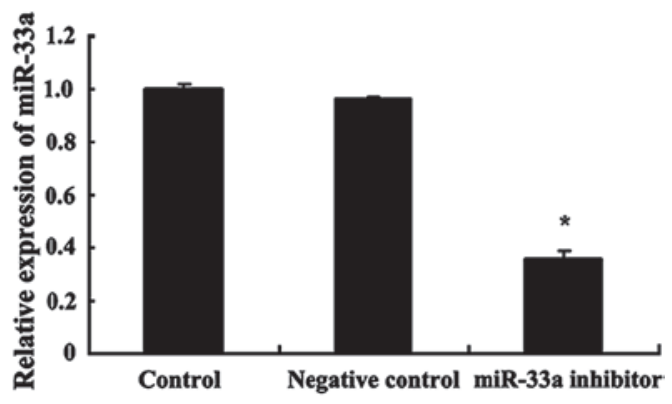

C

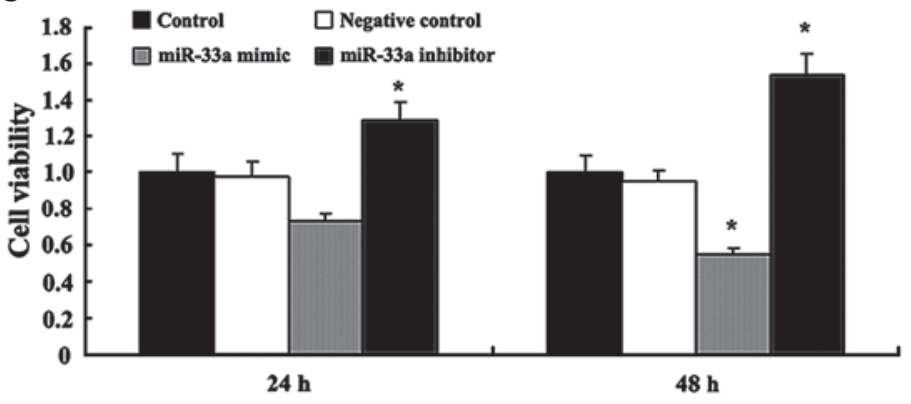

D

Negative control

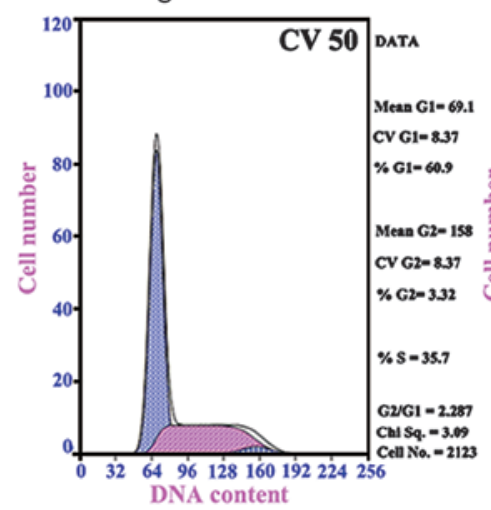

miR-33a mimic

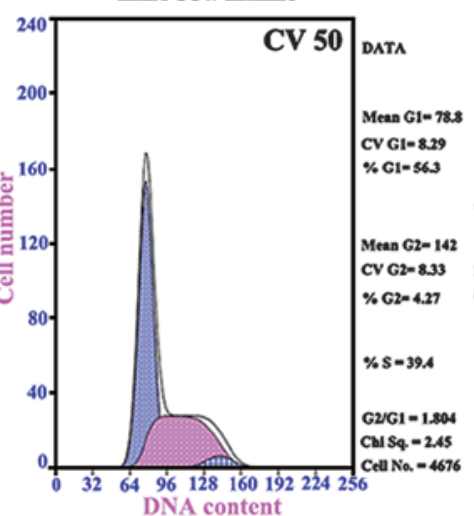

miR-33a inhibitor

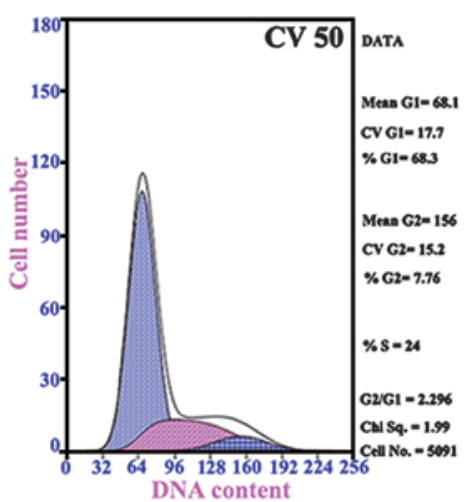

Figure 4. miR-33a inhibits proliferation and regulates the cell cycle in the SGC-7901 gastric cancer cell line. (A and B) SGC-7901 cells were transfected with miScript miR-33a mimic or Allstars negative control small interfering RNA or miScript miR-33a inhibitor, or miScript inhibitor negative control. (C) Cell counting kit-8 proliferation assay was performed on transfected SGC-7901 cells. Transfection with miR-33a significantly inhibited the proliferative capacity of SGC-7901 cells. Values are expressed as the mean \pm standard deviation of three independent experiments. ${ }^{*} \mathrm{P}<0.05 ;{ }^{* *} \mathrm{P}<0.01$ vs. control. (D) miR-33a causes cell cycle arrest in G1 phase. Representative cell cycle distributions of three experiments are shown. miR, microRNA; CV50, coefficient of variation.

Previous studies regarding the function of miR-33a in cancer have reported conflicting results. A recent study reported that miR-33a was upregulated in human colon cancer stem cells (SW1116csc) (18). miR-33a induced tumorigenesis by 
Table V. Spearman correlation of miR-33a with the expression of CDK6, CCND1, PIM1and P53 in gastric cancer specimens $(\mathrm{n}=57)$.

\begin{tabular}{lcr}
\hline Gene & $\mathrm{r}$ & P-value \\
\hline CDK6 & -0.353 & 0.010 \\
CCND1 & -0.323 & 0.014 \\
PIM1 & -0.282 & 0.033 \\
P53 & -0.095 & 0.482 \\
\hline
\end{tabular}

A

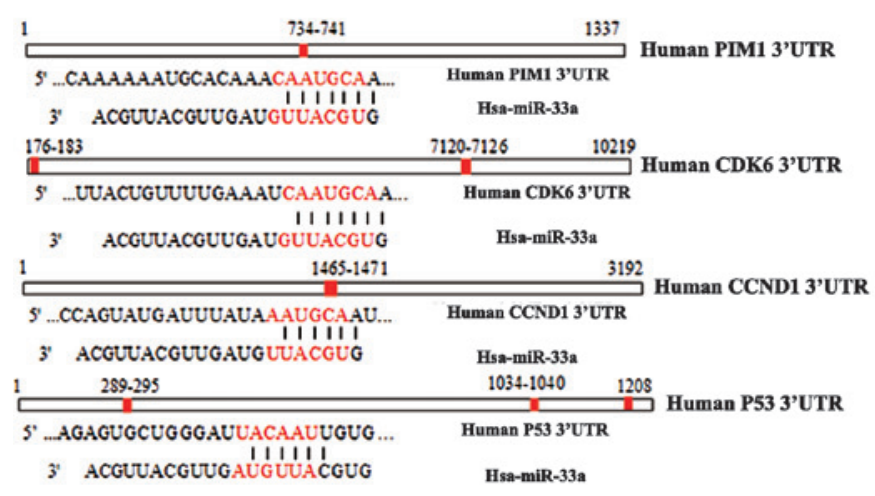

C

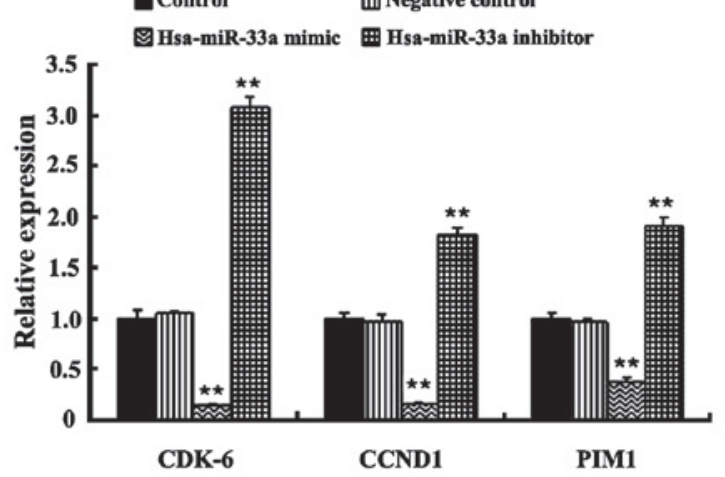

B

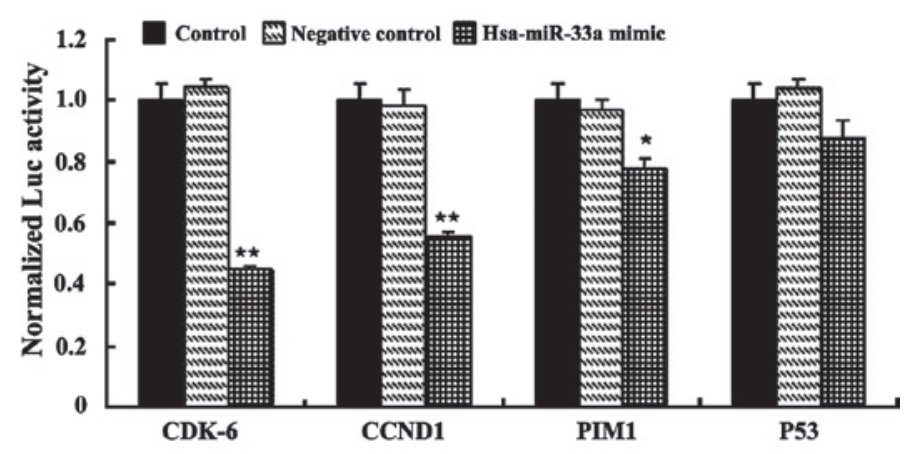

D

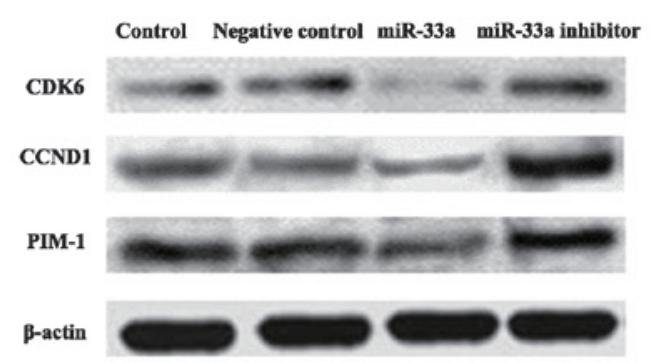

Figure 5. miR-33a directly targets CDK6, CCND1 and PIM1. (A) The 3'UTRs of CDK6, CCND1,PIM1 and P53 have putative binding sites for miR-33a. (B) Normalized activity of luciferase reporter with the CDK6, CCND1, PIM1 and P53 3'UTR in SGC-7901 cells in the presence of co-transfected Allstars negative control small interfering RNA or miR-33a mimic. Effects of miR-33a on the (C) mRNA and (D) protein expression of CDK6, CCND1 and PIM1 in SGC-7901 were detected by reverse transcription quantitative polymerase chain reaction and western blot analysis, respectively. Values are expressed as the mean \pm standard deviation of three independent experiments. $\mathrm{P}<0.05,{ }^{\text {,* }} \mathrm{P}<0.01$ vs. control. miR, microRNA; UTR, untranslated region; CCND1, cyclin D1; Luc, luciferase; Hsa, Homo sapiens.

A

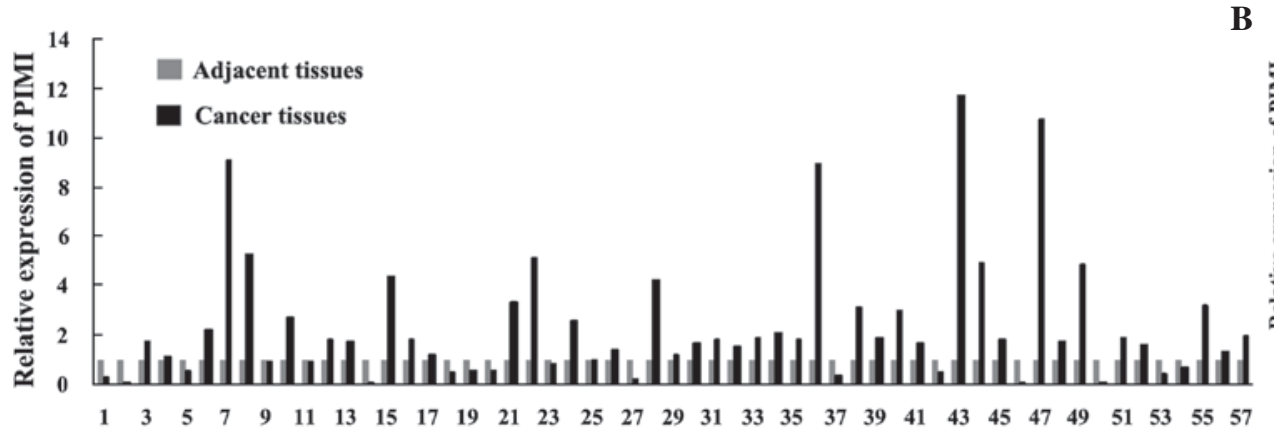

B

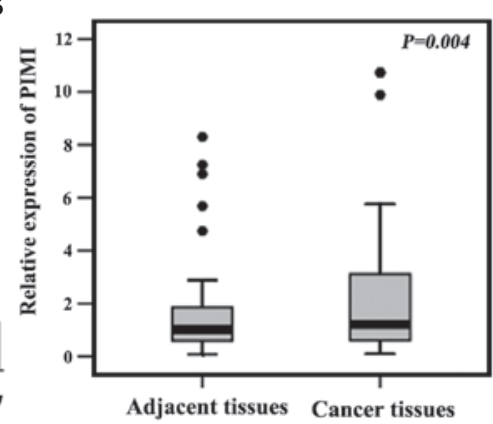

Figure 6. Differential expression of PIM1 in gastric cancer tissues. (A) Reverse transcription quantitative polymerase chain reaction analysis of gastric cancer tissues and paired adjacent tissues showing significantly increased PIM1 expression in gastric cancer tissues. Expression in paired adjacent tissues was set as 1. (B) Box plot analysis of differential PIM1 expression in gastric cancer tissues and paired adjacent tissues showing a significantly higher expression in gastric cancer tissues (Wilcoxon signed ranks test). 
decreasing p53-mediated apoptosis (23). In addition, a recent study indicated that miR-33a promoted osteosarcoma-cell resistance to cisplatin by downregulating TWIST (19). By contrast, a few studies demonstrated that miR-33a functioned as tumor-suppressor to inhibit metastasis $(16,22)$ and proliferation $(24,25,42)$ in numerous cancer types. These findings indicated that the function of miR-33a in cancer is not universal and that it may be cell type-specific. The present study further investigated the roles of miR-33a in gastric cancer, indicating that miR-33a inhibited the proliferation of SGC-7901 gastric cancer cells due to causing cell cycle arrest in $G_{1}$ phase.

miRNAs have roles of post-transcriptional regulation by inhibiting the expression of their target genes. miR-33a regulates cholesterol levels by targeting Abca1, Abcg1 and Npc1 (9-11) as well as fatty acid metabolism by targeting Ampk, Cpt1a, Crot, Hadhb and Sirt6 $(8,12)$. However, various studies reported a diversity of miR-33a target genes involved in cancer. For instance, p53 was reported as one of the target genes of miR-33a (23). Another study reported that PIM1 was one of the target genes of miR-33a, but not p53 or CDK6 (25). A further study showed that CDK6 and CCND1 were the target genes of miR-33a (24). In the present study, Luciferase reporter assays showed that in SGC-7901 cells, miR-33a directly targeted CDK6, CCND1 and PIM1, but not p53. These results suggested that the effect of miR-33 on target genes and cancer cell viability may be cell type-specific. In SGC-7901 cells overexpressing miR-33a, mRNA and protein levels of CDK6 and CCND1 were decreased to a greater extent than PIM1, which may be the reason for the observed cell cycle arrest in G1 phase, but not in G2 phase. To confirm this pathway in gastric cancer patients, the expression of CDK6, CCND1 and PIM1 was assessed in gastric cancer specimens, showing that miR-33a expression was negatively correlated to CDK6, CCND1 and PIM1. The expression levels of PIM1, but not those of CDK6 and CCND1, were significantly higher in gastric cancer tissues than those in their matched adjacent tissues. As to the differences between the results for cells and clinical specimens, additional mechanisms to the miR-33a/CDK6/CCND1 pathway, possibly associated with the tumor microenvironment, may have been involved in tumors from patients with gastric cancer, which require to be further investigated. A previous study reported that transforming growth factor (TGF)- $\beta$ inhibited the expression of CDK6 (43), and our group also identified that TGF- $\beta$ was upregulated in gastric cancer tissues (data not shown). The results of the present study proved that miR-33a exerted its effects by directly interacting with CDK6, CCND1 and PIM1 in gastric cancer cells and mostly through PIM1 in gastric cancer patients.

In conclusion, the present study showed that miR-33a inhibits the proliferation of gastric cancer cells by directly targeting CDK6, CCND1 and PIM1. Analysis of tumor samples from gastric cancer patients showed that the miR-33a/PIM1 interaction was the most clinically relevant pathway involved. miR-33a may be utilized as a valuable biomarker for gastric cancer and may resemble a potent therapeutic target.

\section{References}

1. Filipowicz W, Bhattacharyya SN and Sonenberg N: Mechanisms of post-transcriptional regulation by microRNAs: Are the answers in sight? Nat Rev Genet 9: 102-114, 2008.
2. Shi M, Liu D, Duan H, Shen B and Guo N: Metastasis-related miRNAs, active players in breast cancer invasion and metastasis. Cancer Metastasis Rev 29: 785-799, 2010.

3. Meng F, Henson R, Wehbe-Janek H, Smith H, Ueno Y and Patel T: The MicroRNA let-7a modulates interleukin-6-dependent STAT-3 survival signaling in malignant human cholangiocytes. J Biol Chem 282: 8256-8264, 2007.

4. Fassina A, Cappellesso R, Simonato F, Siri M, Ventura L, Tosato F, Busund LT, Pelizzo MR and Fassan M: A 4-MicroRNA signature can discriminate primary lymphomas from anaplastic carcinomas in thyroid cytology smears. Cancer Cytopathol 122: 274-281, 2014.

5. Wang Q, Huang Z, Guo W, Ni S, Xiao X, Wang L, Huang D Tan C, Xu Q, Zha R, et al: MicroRNA-202-3p inhibits cell proliferation by targeting ADP-ribosylation factor-like $5 \mathrm{~A}$ in human colorectal carcinoma. Clin Cancer Res 20: 1146-1157, 2014.

6. Nohata N, Sone Y, Hanazawa T, Fuse M, Kikkawa N, Yoshino H, Chiyomaru T, Kawakami K, Enokida H, Nakagawa M, et al: miR-1 as a tumor suppressive microRNA targeting TAGLN2 in head and neck squamous cell carcinoma. Oncotarget 2: 29-42, 2011.

7. Huang S, Chen Y, Wu W, Ouyang N, Chen J, Li H, Liu X, Su F, Lin L and Yao Y: miR-150 promotes human breast cancer growth and malignant behavior by targeting the pro-apoptotic purinergic P2X7 receptor. PLoS One 8: e80707, 2013.

8. Gerin I, Clerbaux LA, Haumont O, Lanthier N, Das AK, Burant CF, Leclercq IA, MacDougald OA and Bommer GT: Expression of miR-33 from an SREBP2 intron inhibits cholesterol export and fatty acid oxidation. J Biol Chem 285: 33652-33661, 2010.

9. Marquart TJ, Allen RM, Ory DS and Baldán A: miR-33 links SREBP-2 induction to repression of sterol transporters. Proc Natl Acad Sci USA 107: 12228-12232, 2010.

10. Najafi-Shoushtari SH, Kristo F, Li Y, Shioda T, Cohen DE, Gerszten RE and Näär AM: MicroRNA-33 and the SREBP host genes cooperate to control cholesterol homeostasis. Science 328: $1566-1569,2010$.

11. Rayner KJ, Suárez Y, Dávalos A, Parathath S, Fitzgerald ML, Tamehiro N, Fisher EA, Moore KJ and Fernández-Hernando C: MiR-33 contributes to the regulation of cholesterol homeostasis. Science 328: 1570-1573, 2010.

12. Dávalos A, Goedeke L, Smibert P, Ramírez CM, Warrier NP, Andreo U, Cirera-Salinas D, Rayner K, Suresh U, Pastor-Pareja JC, et al: $\mathrm{miR}-33 \mathrm{a} / \mathrm{b}$ contribute to the regulation of fatty acid metabolism and insulin signaling. Proc Natl Acad Sci USA 108: 9232-9237, 2011.

13. Wijesekara N, Zhang LH, Kang MH, Abraham T, Bhattacharjee A, Warnock GL, Verchere CB and Hayden MR: miR-33a modulates ABCA1 expression, cholesterol accumulation and insulin secretion in pancreatic islets. Diabetes 61: 653-658, 2012 .

14. Ramírez CM, Goedeke L, Rotllan N, Yoon JH, Cirera-Salinas D, Mattison JA, Suárez Y, de Cabo R, Gorospe M and Fernández-Hernando C: MicroRNA 33 regulates glucose metabolism. Mol Cell Biol 33: 2891-2902, 2013.

15. Goedeke L, Vales-Lara FM, Fenstermaker M, Cirera-Salinas D, Chamorro-Jorganes A, Ramírez CM, Mattison JA, de Cabo R, Suárez Y and Fernández-Hernando C: A regulatory role for microRNA $33^{*}$ in controlling lipid metabolism gene expression. Mol Cell Biol 33: 2339-2352, 2013.

16. Rice SJ, Lai SC, Wood LW, Helsley KR, Runkle EA, Winslow MM and Mu D: MicroRNA-33a mediates the regulation of high mobility group AT-hook 2 gene (HMGA2) by thyroid transcription factor 1 (TTF-1/NKX2-1). J Biol Chem 288: 16348-16360, 2013.

17. Fang Y, Feng Y, Wu T, Srinivas S, Yang W, Fan J, Yang C and Wang S: Aflatoxin B1 negatively regulates Wnt/B-catenin signaling pathway through activating miR-33a. PLoS One 8: e73004, 2013

18. Yu XF, Zou J, Bao ZJ and Dong J: miR-93 suppresses proliferation and colony formation of human colon cancer stem cells. World J Gastroenterol 17: 4711-4717, 2011.

19. Zhou Y, Huang Z, Wu S, Zang X, Liu M and Shi J: miR-33a is up-regulated in chemoresistant osteosarcoma and promotes osteosarcoma cell resistance to cisplatin by down-regulating TWIST. J Exp Clin Cancer Res 33: 12, 2014.

20. Zhang T, Han G, Wang Y, Chen K and Sun Y: MicroRNA expression profiles in supraglottic carcinoma. Oncol Rep 31: 2029-2034, 2014 
21. LiX,LuoF,LiQ,Xu M,Feng D,Zhang G and Wu W: Identification of new aberrantly expressed miRNAs in intestinal-type gastric cancer and its clinical significance. Oncol Rep 26: 1431-1439, 2011.

22. Kuo PL, Liao SH, Hung JY, Huang MS and Hsu YL: MicroRNA-33a functions as a bone metastasis suppressor in lung cancer by targeting parathyroid hormone related protein. Biochim Biophys Acta 1830: 3756-3766, 2013.

23. Herrera-Merchan A, Cerrato C, Luengo G, Dominguez O, Piris MA, Serrano M and Gonzalez S: miR-33-mediated downregulation of p53 controls hematopoietic stem cell self-renewal. Cell Cycle 9: 3277-3285, 2010.

24. Cirera-Salinas D, Pauta M, Allen RM, Salerno AG, Ramírez CM, Chamorro-Jorganes A, Wanschel AC, Lasuncion MA, Morales-Ruiz M, Suarez Y, et al: MiR-33 regulates cell proliferation and cell cycle progression. Cell Cycle 11: 922-933, 2012.

25. Thomas M, Lange-Grünweller K, Weirauch U, Gutsch D, Aigner A, Grünweller A and Hartmann R: The proto-oncogene Pim-1 is a target of miR-33a. Oncogene 31: 918-928, 2012.

26. Jemal A, Bray F, Center MM, Ferlay J, Ward E and Forman D: Global cancer statistics. CA Cancer J Clin 61: 69-90, 2011.

27. Kang YK, Kang WK, Shin DB, Chen J, Xiong J, Wang J, Lichinitser M, Guan Z, Khasanov R, Zheng L, et al: Capecitabine/cisplatin versus 5-fluorouracil/cisplatin as first-line therapy in patients with advanced gastric cancer: A randomised phase III noninferiority trial. Ann Oncol 20: 666-673, 2009.

28. Ajani JA, Rodriguez W, Bodoky G, Moiseyenko V, Lichinitser M Gorbunova V, Vynnychenko I, Garin A, Lang I and Falcon S: Multicenter phase III comparison of cisplatin/S-1 with cisplatin/infusional fluorouracil in advanced gastric or gastroesophageal adenocarcinoma study: The FLAGS trial. J Clin Oncol 28: 1547-1553, 2010.

29. Ohtsu A, Shah MA, Van Cutsem E, Rha SY, Sawaki A, Park SR Lim HY, Yamada Y, Wu J, Langer B, et al: Bevacizumab in combination with chemotherapy as first-line therapy in advanced gastric cancer: A randomized, double-blind, placebo-controlled phase III study. J Clin Oncol 29: 3968-3976, 2011.

30. Guo W, Dong Z, Guo Y, Chen Z, Kuang G and Yang Z: Methylation-mediated repression of GADD45A and GADD45G expression in gastric cardia adenocarcinoma. Int J Cancer 133: 2043-2053, 2013

31. Kong D, Zheng T, Zhang M, Wang D, Du S, Li X, Fang J and Cao X: Static mechanical stress induces apoptosis in rat endplate chondrocytes through MAPK and mitochondria-dependent caspase activation signaling pathways. PLoS One 8: e69403, 2013.
32. Tang H, Deng M, Tang Y, Xie X, Guo J, Kong Y, Ye F, Su Q and Xie X: miR-200b and miR-200c as prognostic factors and mediators of gastric cancer cell progression. Clin Cancer Res 19: 5602-5612, 2013

33. Zhou X, Sang M, Liu W, Gao W, Xing E, Lü W, Xu Y, Fan X, Jing S and Shan B: LMO4 inhibits p53-mediated proliferative inhibition of breast cancer cells through interacting p53. Life Sci 91: 358-363, 2012.

34. Nurse P: Checkpoint pathways come of age. Cell 91: 865-867, 1997.

35. Rivadeneira DB, Mayhew CN, Thangavel C, Sotillo E, Reed CA, Graña X and Knudsen ES: Proliferative suppression by CDK4/6 inhibition: Complex function of the retinoblastoma pathway in liver tissue and hepatoma cells. Gastroenterology 138: 1920-1930, 2010.

36. Bachmann M,Hennemann H, Xing PX, Hoffmann I and Möröy T: The oncogenic serine/threonine kinase Pim-1 phosphorylates and inhibits the activity of Cdc25C-associated kinase 1 (C-TAK1): A novel role for Pim-1 at the G2/M cell cycle checkpoint. J Biol Chem 279: 48319-48328, 2004.

37. Cen B, Mahajan S, Wang W and Kraft AS: Elevation of receptor tyrosine kinases by small molecule AKT inhibitors in prostate cancer is mediated by Pim-1. Cancer Res 73: 3402-3411, 2013.

38. Vogelstein B, Lane D and Levine AJ: Surfing the p53 network. Nature 408: 307-310, 2000.

39. Waldman T, Kinzler KW and Vogelstein B: p21 is necessary for the p53-mediated G1 arrest in human cancer cells. Cancer Res 55: 5187-5190, 1995.

40. Baselga-Escudero L, Arola-Arnal A, Pascual-Serrano A, Ribas-Latre A, Casanova E, Salvadó MJ, Arola L and Blade C: Chronic administration of proanthocyanidins or docosahexaenoic acid reverses the increase of miR-33a and miR-122 in dyslipidemic obese rats. PLoS One 8: e69817, 2013.

41. Wang JM, Zhou JJ, Zheng Q, Gan H and Wang H: Dialysis method alters the expression of microRNA-33a and its target genes ABCA1, ABCG1 in THP-1 macrophages. Ther Apher Dial 18: 44-50, 2014.

42. Li T, Francl JM, Boehme S and Chiang JY: Regulation of cholesterol and bile acid homeostasis by the cholesterol $7 \alpha$-hydroxylase/steroid response element-binding protein 2/microRNA-33a axis in mice. Hepatology 58: 1111-1121, 2013.

43. Zhang F, Taipale M, Heiskanen A and Laiho M: Ectopic expression of Cdk6 circumvents transforming growth factor-beta mediated growth inhibition. Oncogene 20: 5888-5896, 2001. 